\title{
Gestão por competências: métodos e técnicas para mapeamento de competências
}

Hugo Pena Brandão e Carla Patricia Bahry

\section{Introdução}

A gestão por competências tem sido apontada como modelo gerencial alternativo aos instrumentos tradicionalmente utilizados pelas organizações. Baseando-se no pressuposto de que o domínio de certos recursos é determinante do desempenho superior de pessoas e organizações, esse modelo propõe-se fundamentalmente a gerenciar o gap ou lacuna de competências, ou seja, a reduzir ao máximo a discrepância entre as competências necessárias à consecução dos objetivos organizacionais e aquelas já disponíveis na organização.

A redução ou eliminação de eventuais lacunas de competências está condicionada ao mapeamento das competências necessárias à consecução da estratégia organizacional. Para realizar esse mapeamento, a organização pode fazer uso de diversos métodos e técnicas de pesquisa social, que auxiliam na realização de um diagnóstico, permitindo não apenas a identificação da lacuna de competências, mas também o planejamento de ações de recrutamento, seleção e desenvolvimento profissional, por exemplo. 
Este artigo tem como objetivo apresentar métodos, técnicas e instrumentos que podem ser utilizados para mapeamento de competências em organizações públicas e privadas. Para isso, apresentam-se, a seguir, uma revisão da literatura sobre o conceito de competência, o mapeamento de competências e a gestão por competências e discutem-se seus pressupostos e suas aplicações. Ao final, são levantadas implicações da gestão por competências para o setor público e são apresentadas recomendações práticas.

\section{A noção de competência}

O surgimento de modelos de gestão baseados na noção de competência e, por conseguinte, sua incorporação ao ambiente organizacional fizeram com que o termo competênciaadquirisse diferentes conotações, conforme relata McLagan (1997). Não se pretende aqui discutir as diversas correntes teóricas e as abordagens conceituais existentes, pois o assunto já foi suficientemente tratado por muitos autores, tais como Brandão e Guimarães (2001), Dutra (2004) e Fleury e Fleury (2001).

Assim, para efeito deste artigo, as competências humanas ou profissionais são entendidas como combinações sinérgicas de conhecimentos, habilidades e atitudes, expressas pelo desempenho profissional em determinado contexto ou em determinada estratégia organizacional (CARBONEet al, 2005. Freitas; Brandão, 2005). Essas competências são reveladas quando as pessoas agem diante das situações profissionais com as quais se deparam (ZARIFIAN, 1999) e servem como ligação entre as condutas individuais e a estratégia da organização (Prahalad; Hamel, 1990).

Sob essa perspectiva, a aplicação de conhecimentos, habilidades e atitudes no trabalho gera um desempenho profissional. Esse desempenho, por sua vez, é expresso pelos comportamentos que a pessoa manifesta no trabalho e pelas conseqüências desses comportamentos, em termos de realizações e resultados (GILBERT, 1978). O desempenho da pessoa, então, representa uma expressão de suas competências (Brandão; Guimarães, 2001). Por essa razão, alguns autores, como Santos (2001) e Whiddett e Hollyforde (1999), descrevem as competências humanas sob a forma de comportamentos observáveis no trabalho.

É importante ressaltar, ainda, que alguns autores associam o conceito de competência não apenas a pessoas, mas também a equipes de trabalho ou mesmo a organizações. É o caso de Le Boterf (1999), para quem em cada equipe de trabalho manifesta-se uma competência coletiva, que emerge das relações sociais que se estabelecem no grupo e da sinergia entre as competências individuais de seus membros. Prahalad e Hamel (1990), por sua vez, elevam o conceito ao nível organizacional, referindo-se à competência como um atributo da organização. É possível, então, c lassificar as competências como humanas ou profissionais (aquelas relacionadas a indivíduos ou a pequenas equipes de trabalho) e organizacionais (aquelas inerentes a toda a organização ou a uma de suas unidades produtivas).

\section{A gestão por competências}

A gestão por competências propõese a orientar esforços para planejar, captar, desenvolver e avaliar, nos diferentes níveis da organização - individual, grupal e organizacional -, as competências necessárias à consecução de seus objetivos, conforme explicam Brandão e Guimarães (2001). 


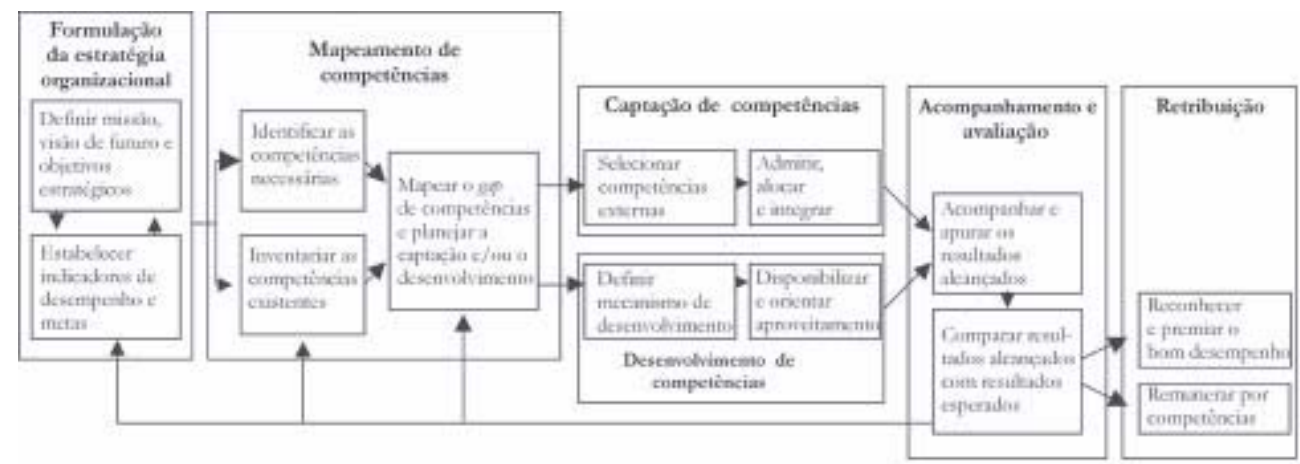

Figura 1: Construção de sistema de indicadores para ciclo de políticas públicas

O diagrama disposto na Figura 1 apresenta as principais etapas ou fases desse processo.

Trata-se de um processo contínuo, que tem como etapa inicial a formulação da estratégia da organização, oportunidade em que são definidos sua missão, sua visão de futuro e seus objetivos estratégicos. Em seguida, são definidos os indicadores de desempenho e as metas, com base nos objetivos estratégicos estabelecidos.

Segundo Carbone e outros (2005), uma vez formulada a estratégia organizacional, torna-se possível realizar o mapeamento de competências, o que constitui a segunda etapa do processo. $\mathrm{O}$ mapeamento objetiva identificar o gap ou lacuna de competências, isto é, a diferença entre as competências necessárias para concretizar a estratégia formulada e as competências internas já disponíveis na organização, conforme será discutido no próximo tópico.

É importante ressaltar que, na ausência de ações de captação ou desenvolvimento de competências, por parte da organização, essa lacuna tende a crescer. Isso porque a complexidade do ambiente no qual as organizações estão inseridas faz com que sejam exigidas cada vez mais novas competências. As próprias competências internas, já disponíveis na organização, podem

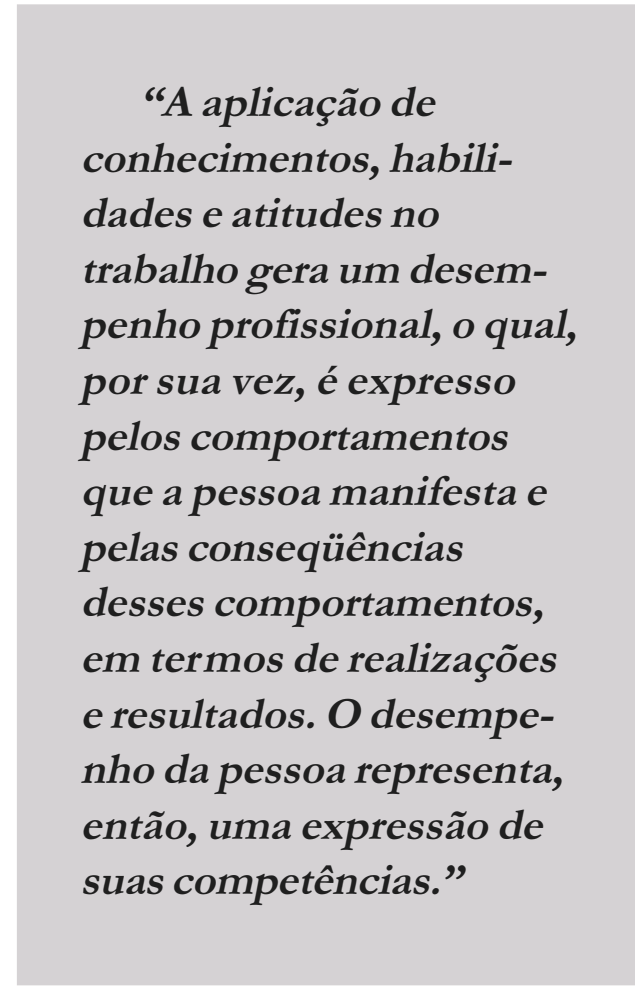

tornar-se obsoletas com o passar do tempo. Por isso, é fundamental realizar periodicamente o mapeamento e planejar a captação e o desenvolvimento de competências.

Segundo Brandão e Guimarães (2001), a captação diz respeito à seleção de competências externas e à sua integração ao ambiente organizacional, que pode darse, no nível individual, por intermédio de ações de recrutamento e seleção de pessoas 
e, no nível organizacional, por meio de parcerias ou alianças estratégicas.

O desenvolvimento, por sua vez, referese ao aprimoramento das competências internas disponíveis na organização, que ocorre, no nível individual, por meio da aprendizagem e, no nível organizacional, por intermédio de investimentos em pesquisa (Brandão; Guimarães, 2001). A aprendizagem, portanto, é o meio pelo qual são desenvolvidas as competências profissionais, enquanto o desempenho da pessoa no trabalho representa uma manifestação da sua competência, ou seja, uma expressão daquilo que a pessoa aprendeu (FreItAs; BRANDÃO, 2005).

$\mathrm{Na}$ etapa de acompanhamento e avaliação, monitoram-se a execução de planos operacionais e de gestão e os respectivos indicadores de desempenho, visando identificar e corrigir eventuais desvios. Ao final do ciclo, são a purados os resultados alcançados e comparados com os que eram esperados.

Finalmente, na etapa de retribuição, a organização poderia reconhecer, premiar e remunerar, de forma diferenciada, as pessoas, equipes de trabalho e unidades produtivas que mais contribuíram para a consecução dos resultados planejados, o que serviria de estímulo à manutenção de comportamentos desejados e à correção de eventuais desvios.

No processo de gestão por competências, conforme ilustra a Figura 1, a etapa de mapeamento de competências é de fundamental importância, pois dela decorrem as ações de captação e desenvolvimento de competências, avaliação e retribuição. Considerando a relevância dessa etapa e a carência de literatura que explore o tema em detalhes, o mapeamento de competências será mais bem discutido no próximo tópico.

\section{Mapeamento de competências}

Conforme descrito, o mapeamento de competências tem como propósito identificar o gap ou lacuna de competências, ou seja, a discrepância entre as competências necessárias para concretizar a estratégia corporativa e as competências internas existentes na organização (IENAGA, 1998). O passo inicial desse processo consiste em identificar as competências (organizacionais e profissionais) necessárias à consecução dos objetivos da organização. Para essa identificação, geralmente é realizada, primeiro, uma pesquisa documental, que inclui a análise do conteúdo da missão, da visão de futuro, dos objetivos e de outros documentos relativos à estratégia organizacional (CARBONE et al., 2005). Depois, realiza-se a coleta de dados com pessoas-chave da org anização, para que tais dados sejam cotejados com a análise documental, conforme proposto por Bruno-Faria e Brandão (2003). Podem ser utilizados, ainda, outros métodos e outras técnicas de pesquisa, como, por exemplo, a observação, os grupos focais e os questionários estruturados com escalas de avaliação, como sugerem Guimarães e outros (2001) e Santos (2001).

Antes de discutir cada um dos métodos e técnicas aplicados ao mapeamento de competências, é importante observar alguns cuidados metodológicos que devem ser considerados para a descrição de competências. O mais indicado, segundo Carbone e outros (2005), é descrever as competências profissionais sob a forma de referenciais de desempenho, ou seja, de comportamentos objetivos e passíveis de observação no ambiente de trabalho. Quando a descrição não é clara, as pessoas tendem a dar a cada competência a interpretação que melhor lhes convém (CARBONE et al., 2005). 
A descrição de uma competência, portanto, deve representar um desempenho ou comportamento esperado, indicando o que o profissional deve ser capaz de fazer. Esse comportamento deve ser descrito utilizando-se um verbo e um objetivo de ação ${ }^{1}$. A ele pode ser acrescido, sempre que possível e conveniente, uma condição na qual se espera que o desempenho ocor ra. Pode incluir, ainda, um critério que indique um padrão de qualidade considerado satisfatório, conforme os exemplos dispostos no Quadro 1, a seguir. marcadas". Nesse caso, bastaria dizer: "coordena reuniões";

d) duplicidades, como em "soluciona problemas de forma criatwa e original';

e) abstrações, como, por exemplo, "pensa o inédito, sug erindo idéias que resolvam divergências". Nesse exemplo, seria melhor dizer simplesmente: "sugere idéias para solucionar problemas"; e

f) a utilização de verbos que não expressem uma ação concreta, ou seja, que não representem comportamentos passíveis de observação no trabalho, como,

Quadro 1: Exemplos de condições e critérios associados a competências.

\begin{tabular}{|l|l|l|}
\hline $\begin{array}{l}\text { Comportamento } \\
\text { (Verbo + Objeto da ação) }\end{array}$ & Critério & Condição \\
\hline Realiza análises financeiras & com acurácia & $\begin{array}{l}\text { utilizando diferentes } \\
\text { modelos para estimar o } \\
\text { retorno de investimentos }\end{array}$ \\
\hline $\begin{array}{l}\text { Atende aos cidadãos } \\
\text { (usuários do serviço público) }\end{array}$ & $\begin{array}{l}\text { com presteza e } \\
\text { cordialidade }\end{array}$ & $\begin{array}{l}\text { levando em considera- } \\
\text { ção as suas expectativas } \\
\text { e necessidades }\end{array}$ \\
\hline
\end{tabular}

$\mathrm{Na}$ descrição de competências, devese evitar:

a) a construção de descrições muito longas e a utilização de ter mos técnicos que dificultem a compreensão das pessoas;

b) ambigüidades, como, por exemplo, "implementa modelos de gestão bemsucedidos em outras organizações". Não se sabe, nesse caso, se a pessoa deve ser capaz de "implementar, na organização em que trabalha, modelos de gestão que foram bem-sucedidos em outras organizações", ou, então, "implementar, em outras organizações, modelos de gestão bem-sucedidos". Essa redação é ambígua, dando margem a dupla interpretação;

c) ir relevâncias e obviedades, como, por exemplo, "coordena reuniões que são por exemplo, saber, apreciar, acreditar e pensar, entre outros.

Para obter boas descrições de competências, Bruno-Faria e Brandão (2003) sugerem:

a) utilizar verbos que expressem uma ação concreta, ou seja, que representem comportamentos observáveis no trabalho, como, por exemplo, analisar, organizar, selecionar, comunicar, avaliar e formular;

b) submeter as descrições à crítica de pessoas-chave da organização, visando identificar possíveis inconsistências e inadequações; e

c) realizar a validação semântica das competências descritas, visando garantir que todos os funcionários compreendam o comportamento descrito. 
Com base nessas considerações sobre a descrição de competências, pode-se, então, discutir as principais técnicas de pesquisa e procedimentos utilizados para identificar competências relevantes à consecução dos objetivos organizacionais. Conforme descrito, geralmente primeiro é realizada uma análise dos documentos que compõem o planejamento estratégico da organização. Essa análise de conteúdo da estratégia organizacional objetiva identificar categorias, descrever objetivamente o conteúdo de mensagens e identificar indicadores que permitam fazer inferências a respeito de competências relevantes para a concretização dos objetivos da organização, conforme sugerem Guimarães e outros (2001).

Ao assessorar o mapeamento de competências em um órgão público, BrunoFaria e Brandão (2003) fizeram uma análise detalhada do conteúdo de documentos que compunham sua estratégia, publicados em portarias e decretos governamentais. O órgão era responsável pela gestão de funções administrativas em uma unidade da Federação, tendo status de secretaria de Estado. Entre suas a tribuições, figuravam o planejamento, a capacitação e a gestão de servidores públicos para diversos órgãos do governo. $\mathrm{Na}$ visão de futuro dessa secretaria, que expressava a situação futura desejada por ela para um período aproximado de três anos (amplitude temporal da visão), havia, entre outras, as seguintes menções (GDF, 2001, p. 14):

"Recursos físicos, materiais, tecnológicos e financeiros adequados para o desempenho das atividades da secretaria";

"Agentes públicos capacitados, motivados e comprometidos com a excelência dos serviços prestados à sociedade".
Ou seja, ao final desse período, a secretaria esperava possuir todos os recursos necessários ao desempenho de suas funções, assim como prover o Estado de servidores públicos qualificados e comprometidos com a qualidade dos serviços prestados à população. Foram realizadas, então, uma análise e uma interpretação dessa visão de futuro e de outros documentos disponíveis na secretaria. Verificou-se que, se o processo de desenvolvimento dos servidores ficasse limitado a ações formais de capacitação, as quais estavam sujeitas a limitações orçamentárias, dificilmente a secretaria conseguiria concretizar a sua visão de futuro. Para conseguir os recursos de que necessitava e promover a capacitação dos servidores, seria preciso não só estabelecer parcerias com a sociedade civil organizada e o segmento empresarial, mas também estimular o autodesenvolvimento e a profissionalização dos servidores. Podese inferir, então, que, para concretizar a visão de futuro, alguns servidores dessa secretaria deveriam possuir, entre outras, as seguintes competências profissionais:

- realiza parcerias com a sociedade civil e o segmento empresarial, visando obter recursos necessários à consecução dos objetivos da secretaria; e

- planeja e implementa ações de comunicação interna (endomarketing) para estimular o autodesenvolvimento e a profissionalização dos servidores públicos.

A entrevista constitui outra técnica de pesquisa bastante aplicada ao mapeamento de competências. Geralmente é utilizada para cotejar a percepção dos entrevistados com os dados apurados na análise documental, visando identificar as competências relevantes à organização, a exemplo do mapeamento realizado por Brandão e outros (2002) em um banco público. 
Nesse caso, o entrevistador seleciona as pessoas a serem entrevistadas entre aquelas que possuem maior conhecimento da organização. Depois, formula um roteiro de perguntas e agenda as entrevistas. Ao iniciar a coleta de dados, o entrevistador deve expor ao respondente os objetivos do trabalho e a importância de sua colaboração, bem como garantir o anonimato para quaisquer declarações. Deve-se, ainda, valorizar a participação do respondente, buscando uma relação de empatia, conforme descrito por Lodi (1991).

Para compor o roteiro da entrevista, Carbone e outros (2005) sugerem a utilização de questões, como, por exemplo: Que competências profissionais você julga relevantes para a consecução dos objetivos organizacionais? Para que a organização consiga concretizar sua estratégia, os funcionários devem ser capazes de quê? Como você reconhece um desempenho competente?

É recomendável gravar os depoimentos e registrar notas que facilitem a compreensão das respostas. Findas as entrevistas, as respostas devem ser transcritas e analisadas, conforme sugerem Richardson e outros (1999), visando identificar e descrever, de forma objetiva, as competências mencionadas pelos entrevistados como relevantes à organização. $\mathrm{Na}$ análise do conteúdo das entrevistas, devese interpretar o discurso do entrevistado, procurando identificar aspectos subjacentes às respostas (CARBOnE et al., 2005).

No mapeamento de competências relevantes a atendentes de um grande banco público, por exemplo, Brandão e outros (2001) formularam a seguinte pergunta: "Que competências você julga importantes para que atendentes e caixas possam prestar um atendimento de excelência ao cliente?”. O respondente, um

executivo do banco, deu o depoimento a seguir:

"Acho muito importante o atendente interpretar o comportamento do consumidor. Você sabia que lá em Belo Horizonte um funcionário percebeu que homens recentemente divorciados são mais predispostos a adquirir planos de previdência privada para seus filhos? Isto porque se sentem

"A complexidade do ambiente no qual as organizações estão inseridas faz com que sejam exigidas cada vez mais novas competências. Aquelas já disponíveis na organização podem tornar-se obsoletas. $E$ fundamental realizar periodicamente o mapeamento e planejar a captação e o desenvolvimento de competência."

'culpados' por estarem pouco presentes na educação das crianças. Dessa forma, buscam alguma compensação para os filhos, algo que possa contribuir para o seu bem-estar futuro."

Realizada a análise do conteúdo dessa e de outras respostas, os autores chegaram à descrição das competências profissionais consideradas relevantes para os atendentes 
e caixas do banco estudado, sendo uma delas assim descrita: "Identifica oportunidades negociais a partir do conhecimento do comportamento do consumidor".

É importante, ainda, verificar a freqüência com que cada competência é mencionada nas entrevistas, visto que o número de menções realizadas a respeito de determinado item é um indicativo da sua relevância, conforme sugerem Brandão e outros (2002).

Muitas vezes, nem o pesquisador nem os profissionais objeto do estudo dispõem de tempo para entrevistas individuais. Nesse caso, uma alterna tiva é realizar uma entrevista coletiva, também denominada grupo focal ou focus group. Em um grupo focal, o entrevistador atua como moderador, estimulando e coordenando a discussão dos participantes a respeito de determinado tema, a fim de obter os dados desejados (MATTAR, 1996).

Os grupos geralmente possuem entre 6 e 12 participantes, pois um número superior a esse pode dificultar a expressão de todos os componentes, enquanto um número inferior pode não gerar idéias ou manifestações suficientes. É recomendável, ainda, que os participantes tenham características demográficas e socioeconômicas semelhantes, para que haja identificação e integração entre eles, facilitando a discussão, conforme recomendado por Mattar (1996).

Segundo Carbone e outros (2005), a exemplo do que ocorre na entrevista individual, o entrevistador necessita elaborar um roteiro de questões e estabelecer os procedimentos para registro dos dados, o tamanho e a composição do grupo. A discussão realizada pelo grupo focal deve ser transcrita e analisada, visando identificar quais competências os entrevistados mencionaram como relevantes à organização.
Para identificar o comportamento competente, o pesquisador pode optar, ainda, pela observação. Esta constitui-se em uma análise detalhada do objeto estudado, ou seja, das competências relevantes ao trabalho das pessoas.

Segundo Viegas (1999) e Mattar (1996), a observação pode ser do tipo "participante", quando o investigador atua como se fosse um integrante da equipe de trabalho. Pode, ainda, ser do tipo "não participante", quando o observador não compõe a equipe, atuando apenas como espectador.

Independentemente do tipo de observação realizada, é fundamental, para o bom desenvolvimento do processo de coleta de dados, que seja mantido um relacionamento amistoso e um clima de confiança entre o investigador e os componentes da equipe de trabalho. Por meio da observação, torna-se possível identificar as competências que indivíduos e grupos expressam no trabalho e o grau de importância delas para o exercício de uma atividade.

Carbone e outros (2005) ressaltam que uma das vantagens da observação, no mapeamento de competências, refere-se à possibilidade de verificar detalhes do desempenho de pessoas e grupos, identificando dados que poderiam ser omitidos pelos pesquisados, caso a coleta fosse realizada por meio de entrevistas ou questionários.

O questionário, por sua vez, é talvez a técnica mais utilizada para mapear competências relevantes para um contexto organizacional. A for matação desse instrumento de pesquisa geralmente requer a aplicação prévia de uma ou mais das técnicas já relatadas (análise documental, observação e entrevista), com o objetivo de identificar elementos para compor os itens do questionário, a exemplo dos trabalhos 
realizados no banco público e na secretaria de Estado, mencionados anteriormente.

Nesse caso, o pesquisador identifica, por meio de análise documental e/ou entrevistas, competências consideradas relevantes para a organização. Depois, ordena e descreve essas competências - que deverão compor os itens do questionário -, eliminando ambigüidades, duplicidades e irrelevâncias, conforme mencionado por Brandão e outros (2001). Para a elaboração dos enunciados e itens do instrumento, devese evitar frases longas e expressões técnicas, extremadas ou ne gativas, conforme sugerem Rocha e Christensen (1997), Viegas (1999) e Richardson e outros (1999).

A próxima etapa consiste em definir a escala mais adequada para os respondentes do questionário avaliarem o grau de importância das competências. Segundo Brandão e outros (2001), pode-se utilizar, por exemplo, uma escala do tipo "diferencial semântico", também conhecida como escala de Osgood, que utiliza adjetivos de significados opostos em seus extremos. Nesse caso, o enunciado do questionário poderia ter o formato do Modelo 1.

Outra alternativa é utilizar uma escala tipo Likert para avaliar o grau de importância das competências, conforme sugerido por Carbone e outros (2005). Enquanto na escala de Osgood apenas os pontos extremos da escala recebem rótulos, na escala tipo Likert todos os pontos recebem rótulos específicos, como, por exemplo: 1 - Nada importante; 2 - Pouco importante; 3 - Medianamente importante; 4 Muito importante; 5 - Totalmente importante. Nesse caso, o enunciado do questionário poderia ser o do Modelo 2.

Modelo 1: Por favor, considerando os atuais objetivos da organização em que você trabalha, assinale um número de UM a SEIS, na escala à direita de cada item, a fim de indicar o quão importante você considera cada uma das competências relacionadas a seguir. Lembre-se: quanto mais próximo do número UM você se posicionar, menor o grau de importância da competência, e quanto mais próximo do número SEIS você se posicionar, maior o grau de importância.

\begin{tabular}{|l|lll|}
\hline \multicolumn{1}{|c|}{ Competências } & \multicolumn{3}{|c|}{ Escala - Graus de Importância } \\
\hline $\begin{array}{l}\text { Identifica oportunidades negociais } \\
\text { a partir do conhecimento do } \\
\text { comportamento do consumidor. }\end{array}$ & $\begin{array}{l}\text { Nem um pouco (1) (2) (3) (4) (5) (6) } \\
\text { importante }\end{array}$ & $\begin{array}{l}\text { Extremamente } \\
\text { importante }\end{array}$ \\
\hline $\begin{array}{l}\text { Comunica-se, na forma oral e } \\
\text { escrita, com clareza e objetividade. }\end{array}$ & $\begin{array}{l}\text { Nem um pouco (1) (2) (3) (4) (5) (6) } \\
\text { importante }\end{array}$ & $\begin{array}{l}\text { Extremamente } \\
\text { importante }\end{array}$ \\
\hline
\end{tabular}

Fonte: Brandão (1999), com adaptações.

Modelo 2: Por favor, considerando os atuais objetivos da organização em que você trabalha, assinale um número de UM a CINCO, nos parênteses à dir eita dos itens, utilizando a escala abaixo para indicar o quão importante você considera as competências a seguir relacionadas. Escala: 1 - Nada importante; 2 Pouco importante; 3 - Medianamente importante; 4 - Muito importante; 5 -Totalmente importante.

\begin{tabular}{|l|c|}
\hline \multicolumn{1}{|c|}{ Competências } & $\begin{array}{c}\text { Graus de } \\
\text { Importância }\end{array}$ \\
\hline $\begin{array}{l}\text { Identifica oportunidades negociais a partir do conhecimento do comportamento } \\
\text { do consumidor. }\end{array}$ & $(\quad)$ \\
\hline Comunica-se, na forma oral e escrita, com clareza e objetividade. & $(\quad)$ \\
\hline
\end{tabular}


Definida a escala a ser utilizada (Osgood ou Likert), é importante, então, estabelecer o número de pontos. Alguns pesquisadores, como Rocha e Christensen (1997), sugerem a utilização de escalas com, no mínimo, 4 e, no máximo, 10 intervalos. Alegam que, utilizando-se escalas com menos de 4 pontos, pode não haver diferenciação satisfatória e, com mais de 10 pontos, as pessoas podem ter dificuldade para responder. Se o número de intervalos for ímpar, por sua vez, torna-se possível atribuir uma resposta neutra; se for par, não se admite a neutralidade.

É possível também utilizar uma escala comparativa, em que se compara a importância de uma competência em relação a outra, ou, ainda, uma escala de ordenação, solicitando ao respondente que ordene as competências de acordo com a importância de cada uma, colocando, em primeiro lugar, a competência considerada mais importante e, em último, a menos importante, a exemplo do trabalho realizado por Santos (2001). Nesse caso, o enunciado do questionário poderia ser, por exemplo, o do Modelo 3.

É importante também incluir, ao final do questionário, uma seção destinada aos dados pessoais e profissionais do respon- dente, como, por exemplo: idade, gênero, grau de escolaridade, formação, cargo exercido, tempo de trabalho na organização e outros elementos relevantes, conforme o caso. Tais dados permitem ao pesquisador identificar, por meio de análises estatísticas, por exemplo, se o padrão das respostas dos respondentes do sexo masculino difere do das respostas atribuídas por respondentes do sexo feminino, ou, ainda, se pessoas com formação superior atribuem respostas diferentes das dos respondentes sem formação superior, conforme exemplos disponíveis em Brandão e outros (2001) e Bruno-Faria e Brandão (2003).

Independentemente da escala de avaliação utilizada, é importante realizar uma validação semântica do questionário antes de sua aplicação, conforme sugerido por Pasquali (1997), visando verificar se o enunciado, a escala e os itens do instrumento são compreendidos pelos respondentes. Para realizar essa análise, o pesquisador deve aplicar o questionário em uma pequena amostra e depois entrevistar os respondentes, procurando identificar eventuais dificuldades de resposta, falhas ou incorreções no questionário, eliminar ambigüidades e itens sugestivos, a exemplo do que foi feito por

Modelo 3: Por favor, ordene as competências relacionadas a seguir, de UM a QUATRO, colocando, em primeiro lugar, a competência mais importante e, em último, a menos impor tante para a consecução dos objetivos organizacionais.

\begin{tabular}{|l|c|}
\hline \multicolumn{1}{|c|}{ Competências } & $\begin{array}{c}\text { Ordem de } \\
\text { importância }\end{array}$ \\
\hline $\begin{array}{l}\text { Identifica oportunidades negociais a partir do conhecimento do comportamento } \\
\text { do consumidor. }\end{array}$ & $(\quad)$ \\
\hline $\begin{array}{l}\text { Implementa ações de comunicação interna para estimular o } \\
\text { desenvolvimento profissional }\end{array}$ & $($ ) \\
\hline Comunica-se, na forma oral e escrita, com clareza e objetividade. & $($ ) \\
\hline $\begin{array}{l}\text { Colabora com os colegas de trabalho, visando atingir os objetivos da equipe } \\
\text { em clima de harmonia. }\end{array}$ & $($ ) \\
\hline
\end{tabular}


Brandão e outros (2001) e por Bruno-Faria e Brandão (2003). Realizados os eventuais ajustes ou as eventuais correções no instrumento de pesquisa, o pesquisador pode finalmente aplicá-lo.

Além da identificação das competências necessárias à estratégia organizacional, o mapeamento de competências pressupõe também inventariar as competências internas já disponíveis na organização, com o propósito de identificar a lacuna entre as competências necessárias e as já existentes na organização (CARBONE et al., 2005).

A identificação das competências disponíveis na organização geralmente é realizada por meio de instrumentos de avaliação de desempenho, uma vez que a competência humana é expressa em função do desempenho da pessoa no trabalho, conforme apontado por Brandão e Guimarães (2001).

Uma vez realizado o mapeamento da lacuna de competências, pode-se então planejar e realizar a captação e/ou o desenvolvimento de competências profissionais, visando minimizar essa lacuna, bem como retribuir os profissionais que manifestam, de forma exemplar, as competências necessárias à consecução dos objetivos organizacionais, conforme ilustra a Figura 1 , situada anteriormente .

A seguir, são levantadas as implicações da gestão por competências para o setor público e são apresentadas recomendações de ordem prática.

\section{Considerações finais}

No contexto atual, a eficiência e a eficácia das organizações parecem derivar, cada vez mais, de sua capacidade de desenvolver competências e de integrá-las em torno dos objetivos organizacionais. No setor privado, esse e outros pressupostos afetos à gestão por competências parecem já ter sido incorporados ao ambiente organizacional, fundamentando a prática gerencial.

Isso tem ocorrido sobretudo pelo interesse por modelos de gestão que estimulem a aprendizagem, a adaptação e a inovação, capacidades consideradas essenciais numa conjuntura de aceleração do desenvolvimento tecnológico e de crescente exigência por maiores níveis de produtividade.

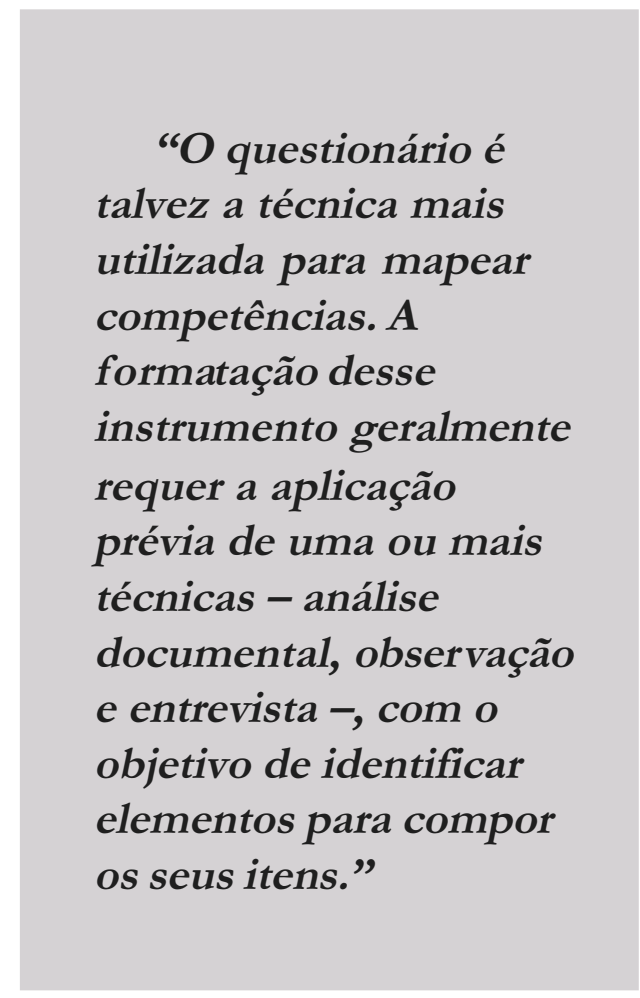

O setor público também tem procurado acompanhar esse movimento, buscando adotar a gestão por competências como alternativa de gestão flexível e empreendedora que possibilite melhorar a qualidade e a eficiência dos serviços públicos (Guimarães, 2000).

Sob essa perspectiva, os métodos e as técnicas de mapeamento de competências descritos neste artigo constituem elemento 
central na gestão por competências, sendo úteis para nortear a orientação profissional, a avaliação de desempenho, o planejamento de carreira e o desenvolvimento de competências dos servidores públicos, entre outros processos, de forma a proporcionar melhorias na qualidade dos serviços prestados à sociedade.

Cabe ressaltar, no entanto, que a eficácia e a aplicabilidade, em organizações públicas, de alguns processos afetos à gestão por competências ainda carecem de discussões mais aprofundadas e investigações empíricas a respeito Embora diversas empresas públicas e agências reguladoras já adotem pressupostos da gestão por competências, como é o caso do Banco do Brasil (Brandão, 2001), da Caixa Econômica Federal (RIBEIRO, 1999), da Empresa Brasileira de Pesquisa Agropecuária (GUIMARÃES et al., 2001) e da Agência Nacional de Energia Elétrica (ÁvILA, 2005), algumas questões parecem permanecer sem respostas: Poderia o setor público instituir formas de remuneração variável baseadas na expressão de competências profissionais? Como realizar concursos públicos com base nas competências mapeadas? Quais as implicações da gestão por competências no provimento de cargos de confiança? Em que medida a expressão de competências profissionais, por parte dos servidores públicos, explicam o desempenho organizacional? Esses e outros aspectos ainda precisam ser mais bem estudados e discutidos.

Constitui também um desafio para as organizações públicas assumir um papel "qualificante", como sugere Zarifian (1999), no sentido de apoiar as iniciativas de desenvolvimento profissional, criar um ambiente que seja propício à aprendizagem e oferecer aos servidores reais oportunidades de crescimento na carreira.

É importante lembrar ainda que, por possuir caráter eminentemente dinâmico, uma competência pode ganhar ou perder relevância ao longo do tempo. É recomendável, então, que a organização defina não apenas o grau de importância atual de suas competências, mas também estime a sua relevância futura. Isso permitiria agir proativamente, desenvolvendo, no presente, competências que serão importantes no futuro.

Finalmente, recomenda-se evitar a adoção de listas genéricas de competências, desprovidas de contexto ou desalinhadas da estratégia organizacional. Cada organização tem suas particularidades, sua cultura, estrutura e estratégia, entre outros elementos, que a distinguem das demais, o que exige a definição de rol de competências contextualizado e adequado às suas necessidades específicas.

(Artigo recebido em maio de 2005 . Versão definitiva em junho de 2005) 


\section{Notas}

${ }^{1}$ Estes procedimentos e exemplos foram sugeridos por Mager (1990), para a formulação de objetivos instrucionais, mas, segundo Carbone e outros (2005), aplicam-se à descrição de competências.

${ }^{2}$ Esse procedimento consiste em entrevistar servidores com diferentes características (gênero, idade, nível de escolaridade, cargo exercido, etc.), objetivando identificar e corrigir eventuais incorreções, falhas, itens sugestivos e ambigüidades, para garantir que as descrições dos comportamentos sejam bem compreendidas pelas pessoas a que se destinam. Ver Pasquali (1997).

\section{Referências bibliográficas}

ÁvilA, Melissa. Gestão de pessoas por competências: uma experiência inovadora no setor público. 2005. Monografia (Especialização em Gestão de Pessoas) - Fundação Getúlio Vargas. Brandẽo, Hugo Pena. Gestão baseada em competências: um estudo sobre competências profissionais na indústria bancária. 1999. Dissertação (Mestrado em Administração) Universidade de Brasília, Brasília.

Brandão, Hugo Pena; Guimarães, Tomás de Aquino. Gestão de competências e gestão de desempenho: tecnologias distintas ou instrumentos de um mesmo constructo? Revista de Administração de Empresas, São Paulo, v. 41, n.1, p. 8-15, jan./mar. 2001.

Brandẽo, Hugo Pena; Guimarães, Tomás de Aquino; Borges-Andrade, Jairo Eduardo. Competências profissionais relevantes à qualidade no atendimento bancário. Revista de Administração Pública, Rio de Janeiro, v. 35, n. 6, p. 61-81, nov./dez. 2001.

. Competências emergentes na indústria bancária: um estudo de caso.

Revista Comportamento Organizacional e Gestão, Lisboa, v. 8, n. 2, p.173-190, out. 2002.

Bruno-Faria, Maria de Fátima; B randẽo, Hugo Pena. Gestão de competências: identificação de competências relevantes a profissionais da área de T\&D de uma organização pública do Distrito Federal. Revista de Administração Contemporânea, Rio de Janeiro, v. 7, n. 3, p. 35-56, jul./set. 2003.

Carbone, Pedro Paulo; Brandão, Hugo Pena; Leite, João Batista Diniz. Gestão por competências e gestão do conhecimento. Rio de Janeiro: Fundação Getúlio Vargas, 2005.

DutRA, Joel Souza. Competências: conceitos e instrumentos para a gestão de pessoas na empresa moderna. São Paulo: Atlas, 2004.

Fleury, Afonso; Fleury, Maria Tereza. Estratégias empresariais e formação de competências: um quebra-cabeça caleidoscópico da indústria brasileira. São Paulo: Atlas, 2001.

Freitas, Isa A.; Brandẽo, Hugo Pena. Trilhas de aprendizagem como estratégia para o desenvolvimento de competências. In: Borges-Andrade; AbBad; Mourão (Orgs.). Treinamento, desenvolvimento e educação no trabalho. Brasília: UnB, 2005 (no prelo).

GILBERT, Thomas F. Human competence: engineering worthy performance. New York: McGraw-Hill Book Company, 1978. 
Guimarães, Tomás de Aquino. A nova administração pública e a abordagem da competência. Revista de Administração Pública, v. 34, n. 3, maio/jun. 2000.

Guimarães, Tomás de Aquino et al. Forecasting core competencies in an R\&D environment. R\&D Management Review, Manchester, UK, v.31, n.3, p.249-255, 2001.

Governo Do Distrito Federal. Secretaria de Estado de Gestão Administrativa. Plano Estratégico. Brasília, mar. 2001.

Ienaga, Celso H. Competence Based Management: Seminário Executivo. São Paulo: Dextron Consultoria Empresarial, 1998.

Le BoterF, Guy. Competénce et navigation professionnelle. Paris: Éditions d'Organisation, 1999. Lodi, João Bosco. A entrevista. teoria e prática. São Paulo: Pioneira, 1991.

Mattar, Fauze Najib. Pesquisa de Marketing. São Paulo: Atlas, 1996. v 1, Metodologia e planejamento.

Mager, Robert F. Preparing instructional objectives: a critical tool in the de velopment of effective instruction. Belmont (EUA): Fearon-Pitman Publishers, 1990.

Mclagan, Patrícia A. Competencies: the next generation. Training \& Development, p. 4047, May, 1997.

Pasquali, Luiz. Psicometria: teoria e aplicações. Brasília: Ed. da Universidade de Brasília, 1997.

Prahalad, C. K.; Hamel, Gary. The core competence of the corporation. Harvard Business Review, Boston, v. 68, n. 3, p. 79-91, May/June, 1990.

Ribeiro, Lore Mânica. Competências organizacionais e humanas de uma organização financeira estatal: o ponto de vista de seus gerentes. In: ENANPAD, 23ㅜ 1999 , Foz do Iguaçu. Anais... Foz do Iguaçu: ANPAD, 1999. 1 CD-ROM.

Richardson, Roberto Jarry et al. Pesquisa social: métodos e técnicas. São Paulo: Atlas, 1999.

Rocha, Angela da; Christensen, Carl. Notas sobre a construção de questionários. Rio de Janeiro: Instituto de Pós-Graduação e Pesquisa em Administração-COPPEAD/UFRJ,1997. Mimeografado.

Santos, Armando Cuesta. O uso do método Delphi na criação de um modelo de competências. Revista de Administração, São Paulo, v.36, n. 2, p. 25-32, abr./jun. 2001.

VIEGAs, Waldyr. Fundamentos de metodologia cientifica. Brasília: Paralelo 15; Ed. Universidade de Brasília, 1999.

Whiddett, Steve; Hollyforde, Sarah. The competencies handbook. London: Institute of Personnel and Development, 1999.

Zarifian, Philippe. Objectif compétence: pour une nouvelle logique. Paris: Editions Liaisons, 1999. 


\section{Resumo - Resumen - Abstract}

\section{Gestão por competências: métodos e técnicas para mapeamento de competências Hugo Pena Brandão e Carla Patricia Babry}

A gestão por competências tem sido apontada como alternativa aos modelos gerenciais tradicionalmente utilizados pelas organizações. Propõe-se a orientar esforços para planejar, captar, desenvolver e avaliar, nos diferentes níveis da organização, as competências necessárias à consecução de seus objetivos. Uma das principais etapas desse processo constitui o denominado mapeamento de competências. Este artigo objetiva apresentar métodos, técnicas e instrumentos utilizados para mapeamento de competências em organizações públicas e privadas. Para isso, fazem-se uma revisão da literatura sobre o conceito de competência, o mapeamento de competências e a gestão por competências, discutindo-se seus pressupostos e suas aplicações. Ao final, são levantadas as implicações desse modelo de gestão para o setor público e são apresentadas recomendações práticas.

Palavras-chave: Gestão de pessoas; gestão por competências; mapeamento de competências.

\section{Gestión por competencias: métodos y técnicas para el inventario de competencias Hugo Pena Brandão y Carla Patricia Bahry}

La gestión por competencias es apuntada como alternativa a los modelos gerenciales tradicionalmente utilizados por las organizaciones. Se propone a orientar esfuerzos para planear, captar, desarrollar y evaluar, en los distintos niveles de la organización, las competencias necesarias para la consecución de sus metas. Una de las principales etapas de ese proceso constituye lo denominado inventario de competencias. El objetivo de este artículo es presentar métodos, técnicas y herramientas utilizados para el inventario de competencias en organizaciones públicas y privadas. Por lo tanto, se realiza una revisión de la literatura sobre el concepto de competencia, el inventario de competencia y la gestión por competencias, discutiendo sus postulados y aplicaciones. Al final, destaca las implicaciones de ese modelo de gestión para el sector público y ofrece algunas recomendaciones practicas.

Palabras clave: gestión de recursos humanos, gestión por competencias, inventario de competencias

\section{Competence-based management: methods and techniques of competence mapping Hugo Pena Brandão and Carla Patricia Bahry}

The competence-based management approach has been pointed as an alternative to traditional managerial models used by organizations. It aims to direct efforts towards planning, selecting, developing and assessing, on all organizational levels, the required competencies to achieve the organizational goals. One of the main stages of this process is namely competence mapping. This paper aims to present methods and techniques used to competence mapping in public and private organizations. For this reason, it is presented a review of the literature about competence-based management, concept and mapping of competences, discussing their postulates and applications. In addition, implications to the public sector and practical advices are presented.

Key-words: human resource management, competence-based management, competence mapping. 
Hugo Pena Brandão

Mestre em Administração e Doutorando em Psicologia Social e do Trabalho pela Universidade de Brasília (UnB), Pesquisador Master da Universidade Corporativa Banco do Brasil e Professor-colaborador da Fundação Getúlio Vargas (FGV/Brasília) e do Centro Universitário do Distrito Federal (UniDF).Contato: hugopb@brturbo.com.br.

\section{Carla Patricia Bahry}

Mestre em Administração pela Universidade Federal de Santa Catarina (UFSC) e Analista da Universidade Corporativa Banco do Brasil. Contato: carlabahry@yahoo.com.br. 